\title{
Managing Defense Transformation in Small and Medium-Sized NATO Countries
}

\author{
Dorinel-Ioan Moldovan *
}

\section{Abstract}

Defense transformation in small and medium-sized countries has a dialectical aspect. On one hand, it is a general process that has arisen as a result of the effect of the forces of globalization on domestic security and defense issues. As such, it is identical for all countries, having the same features. On the other hand, as a critical organizational process, defense transformation represents a unique response by each nation's defense institutions, a response that is crafted in order to cope with challenges coming from both internal and external sources. This paper will analyze the challenging dimensions of defense transformation from the perspective of the binomial relationship of willingness and affordability, and will compare the advantages and disadvantages of various approaches. It is obvious that the complexity of the defense transformation process comes from the many questions it raises and requirements it poses, which each country must solve for its own specific context.

Keywords: defense transformation, small and medium-sized countries, budgetary affordability, leaders' willingness, Revolution in Military Affairs, qualitative and quantitative assessment

\section{European Countries: Between NATO and the EU}

Small and medium-sized countries in Europe have perceived a variety ways to address their security issues, from political-military alliances to different types of collaboration and cooperation. In Western and Central Europe, there are the following methods of assuring national security, which can be arranged according to various nations' attitudes toward the European Security and Defense Policy (ESDP) ${ }^{1}$ :

- The Euro-Atlantic view:

o Traditional Euro-Atlantism: this is the approach taken by Denmark and the Netherlands; even though not an EU member, Norway could be included here as well. These countries accept only NATO as the primary security organization in Europe, and do not participate in (or participate with very few military capabilities) in EU military cooperation operations.

o Reflexive Euro-Atlantism: this view characterizes the Baltic States (Estonia, Latvia, Lithuania) and the Visegrad States (Hungary, Czech Republic, Poland, Slovak Republic). Based on the framework presented by Molis (see note 1), even Bulgaria

* Dorinel-Ioan Moldovan is a Lecturer at the National Defense University "Carol I" in Bucharest, Romania.

1 Arunas Molis, "The Role and Interests of Small States in Developing European Security and Defence Policy," Baltic Security \& Defence Review 8 (2006); 86; available at www.bdcol.ee/ fileadmin/docs/bsdr/5-Small\%20States\%20and\%20the\%20ESDP-Arunas\%20Molis.pdf. 
and Romania, considering their joint accession to EU membership on 1 January 2007, could be included here, too. These countries view the ESDP within the wider framework of transatlantic relations, believing that EU actions should complement the actions of NATO.

o Conjunctive Euro-Atlantism: This view is held by Slovenia, Portugal, and Greece. These countries officially declare NATO as their priority in terms of collective security arrangements, but the practical level of support that they are able to provide depends largely on the domestic political situation.

- The Pro-European view: This is the approach that Belgium, Luxembourg, and Cyprus have taken. These countries have as a long-term interest the strategic independence of Europe, not the preservation of the transatlantic community.

- Traditional Neutrality: The familiar view held by Switzerland and/or non-allied states, including Finland, Austria, Ireland, Malta, and Sweden. Because none of the traditionally neutral states de facto is neutral anymore, these countries chose balancing between the EU and NATO as a mean of accumulating their structural power.

In the context of this essay, defense transformation is a policy choice-meaning a specific way of doing something - about making deliberate changes in a country's war fighting capabilities in order to cope with emerging strategic challenges. These changes are fundamental at the level of equipment, doctrine, operational concepts, organizational training and military culture. The alterations accompanying defense transformation are also discontinuous, often being introduced abruptly, suddenly increased, and dramatically advanced. Defense transformation is a process in the evolution of the military establishment, which is at times carried out simultaneously with efforts of force modernization. It is certain that the fundamental changes in equipment implied in force modernization will dramatically influence the organizational structure of the military in suggesting the efficacy of other types of organization than the classic hierarchical structure (such as matrix and network structures) and by placing increased emphasis on externalizing some of the military's traditional activities (outsourcing). ${ }^{2}$

In this respect, related to the debate over what size military concept (large or small) is appropriate for a given country to pursue, Rob de Wijk has proposed a metric for defining the military power of a country in regard to its types of forces. ${ }^{3}$ Even though de Wijk's essay is focused only on NATO countries, it nevertheless offers a useful tool for analyzing the process of transformation in small and medium countries. According to de Wijk, a country could choose to develop one of the following types of forces:

- A full spectrum force comprises the full array of assets and capabilities, allowing a member state to deal with all contingencies. It allows sustained combat operations

2 Prof. John M. Treddenick, "Defense Transformation: Conceptual Aspects," presentation delivered at the Regional Center for Defense Resources Management, Brasov, Romania, 10 April 2006.

3 Rob de Wijk, "The Implications for Force Transformation: The Small Country Perspective," Chapter 6 in Transatlantic Transformations; Equipping NATO for the 21st Century, ed. Daniel S. Hamilton (Washington, D.C.: Center for Transatlantic Relations, 2004), 118-119; available at http://transatlantic.sais-jhu.edu/Publications/transatlantic_transformations_natobook.pdf. 
against an opponent's irregular or regular forces, and [offers the ability] to carry out stability and reconstruction operations in an effort to keep or bring the peace in distant places. A country with a full spectrum force could provide the framework for coalition operations as well. A framework nation provides the backbone of an operation. Other nations plug in.

- Broad expeditionary capabilities allow a country to carry out similar operations, albeit on a more modest scale. Those countries could act as a lead nation for less demanding operations. A lead nation is responsible for planning the campaign; it directs the strategic decision making process and provides the key elements of C4I (Command, Control, Communication, Computers, Intelligence).

- Focused expeditionary capabilities allow countries to contribute to a wide variety of military operations with a limited range of capabilities. Some countries may even be able to act as a lead nation for small stabilization operations in a permissive environment.

- Selective expeditionary capabilities allow countries to contribute with some force elements to coalition operations. The development of niche capabilities is the obvious choice. Niche capabilities are those scarce capabilities that complement and enhance the performance of the entire coalition and cannot usually be commonly owned.

- Stabilization capabilities allow countries to contribute to peace keeping. These countries could help funding collective capabilities. These collectively owned military capabilities, such as AWACS, are a prerequisite for coalition operations. ${ }^{4}$

Based on this classification of military capabilities, de Wijk has sorted the NATO countries as indicated below in Table 1 .

Table 1: The Military Capabilities of NATO Member States: A Qualitative Assessment

Full spectrum force United States

Broad expeditionary United Kingdom, France (after restructuring**), the Netherlands capabilities

Focused expeditionary Spain** and Italy** (after restructuring) capabilities

Selective expeditionary Belgium, Canada, Denmark**, Germany*, Norway capabilities

Stabilization capabilities Poland*, Turkey*

No capabilities $\quad$ Estonia*, Bulgaria*, Czech Republic*, Greece*, Hungary*,

Latvia*, Lithuania*, Luxembourg, Portugal*, Romania*,

Slovenia*, Slovakia*

* - conscript force

** - transition to professional forces or mix of conscripts and professionals

$4 \quad$ Ibid., 118-19. 
Therefore, my real interest in this essay is the definition of capability, because within the context of the much-heralded Revolution in Military Affairs (RMA), capability-based planning is a challenge for transformation efforts. In the U.S. Department of Defense dictionary, capability means "the ability to execute a specified course of action. (A capability may or may not be accompanied by an intention.)" A state must be able to pursue such a course of action, even in cases of unforeseen risks and threats.

More details are included in the definition of military capability, which is given as:

The ability to achieve a specified wartime objective (win a war or battle, destroy a target set). It includes four major components: force structure, modernization, readiness, and sustainability.

a. force structure: Numbers, size, and composition of the units that comprise U.S. defense forces; e.g., divisions, ships, air wings.

b. modernization: Technical sophistication of forces, units, weapon systems, and equipments.

c. unit readiness: The ability to provide capabilities required by the combatant commanders to execute their assigned missions. This is derived from the ability of each unit to deliver the outputs for which it was designed.

d. sustainability: The ability to maintain the necessary level and duration of operational activity to achieve military objectives. Sustainability is a function of providing for and maintaining those levels of ready forces, materiel, and consumables necessary to support military effort. ${ }^{6}$

In the context of transformation, all of these elements are dramatically altered in order to provide greater precision, speed, lethality, and deployability.

According to the definitions of military capability listed above, and based on the events of the last several years, there are questions and debates over which category best describes a given country's situation. Even though this highlights a need to update the ranking, and to gain greater information about defense issues in general, it is still a useful metric to assess the military power and capabilities possessed by NATO countries. At the same time, such a ranking could be applied to other small or medium-sized countries in the Eurasian area as well.

In order to support transformation in defense within the context of the transatlantic relationship, the United States perceives the NRF (NATO Response Force) as a catalyst to developments taking place within the U.S. military, one that has expanded the perspectives of many U.S. defense thinkers on the potential of creating post-modern armed forces. With the rise of the NRF, the Europeans have in effect accepted the U.S. agenda. The reluctance that the NRF has been met with in some quarters in Europe is a product of the capacity and willingness of European states to meet the requirements of the NRF. This is because there is a what can be called a multi-speed phenomenon in Europe, where a few countries have achieved advanced post-modern forces, while a larger group of countries is only able to

5 See www.dtic.mil/doctrine/jel/doddict/; The DOD Dictionary and the Joint Acronyms and Abbreviations master database are managed by the Joint Doctrine Division, J-7, Joint Staff. All approved joint definitions are contained in Joint Publication 1-02, DOD Dictionary of Military and Associated Terms, as amended through 14 April 2006.

6 Ibid. 
contribute to the NRF with niche capabilities and stabilization forces. In the short term, Europe has a significant need for Network Enabled Operations (NEO) that are capable of interfacing with their C4ISR systems (Command, Control, Communication, Computers, Intelligence, Surveillance and Reconnaissance). The need for these NEO capabilities is greater in Europe than is the need for Network Centric Warfare (NCW) capabilities, which would enable countries to conduct their own operations according to their doctrines, operate in a EU context, and maintain interoperability in U.S.-led operations.

Rob de Wijk considers that Europe must create a post-modern force to be a credible instrument in its foreign, security, and defense strategy, capable of high-intensity operations in which it suffers few friendly losses and acceptable levels of collateral damage. Such a force would better match the political culture of a post-modern multi-state system like Europe than does the collection of modern forces that is currently available to the EU and NATO. The European force's strengths could be in unconventional warfare and stabilization operations. Under the rubric of stabilization efforts, European counterinsurgency units could be used as early entry forces during interventions as well. In addition, both the NRF and Battle Groups contribute to improved war-fighting capabilities. Since it is undesirable to train and equip these forces solely for conventional war, within the context of shifting focus on unconventional warfare, the heavy mechanized forces within Europe must be restructured for stabilization and reconstruction.

All these developments point to the urgent need for a coherent and unified European doctrine, and a European military approach to operations. This is particularly critical since, "despite a NATO-first approach and the NRF, developments in the transatlantic relationship and within the EU point to the increasing chance that in some cases the U.S. will not lead nor contribute with vital support assets.",

A useful way of analyzing defense transformation in small and medium-sized NATO countries is based on the role and missions of their armed forces. These are directly connected to:

- A state's geographical position, which generates specific risks, threats, and dangers against a country, obliging it to project its security and defense accordingly

- Political perspectives, approaches, and ambitions, particularly in the case of countries with armed forces under democratic and civil control, which ensure the legal framework governing roles and missions and the funds for defense spending, which in turn influence the structure, doctrine and training, equipment, and technique of the armed forces

- The people who work for the military organization, both military and civilians. ${ }^{8}$

Defense transformation can be studied, understood, and accepted based on official political and defense documents; officials and decision makers' statements in reports and in-

7 De Wijk, "The Implications for Force Transformation," 45-46.

8 See Dr. John L. Clarke, "What Roles and Missions for Europe's Military and Security Forces in the 21st Century?" Marshall Center Paper, No. 7 (August 2005); available at www.marshallcenter.org/site-graphic/lang-en/page-pubs-mcpapers-1/static/xdocs/coll/static/ mcpapers/mc-paper_7-en.pdf. 
terviews and during formal meetings; and through academic studies and research. These might be considered to constitute the qualitative dimension of defense transformation assessment. At the same time, defense transformation must be focused on the variables within any defense organization: the armed force's role in its country; its missions, functions, and tasks; the quality and experience of its people (leaders and managers, subordinates, employees, and followers, interpreting and evaluating their motivation and commitment to transformation); the technology needed (in terms of weapon systems and equipment, technological devices, and additional infrastructure); and the consequent organizational structures.

Changes in these elements will have implications for the country's military culture. At the same time, under the pressure of societal and technological factors, the members of defense organizations who are educated and trained in the new environment resulting from these transformations will act as change agents, debating the role of military obedience as the main military competence. The new environment is characterized by an entrepreneurial culture, requiring that limits on action be defined, rather the ways and means of action. What to do? not How to do it? will be the question. Therefore, the qualitative analysis of the facts (interviews and discussions with leaders about their intentions, defense analysis of figures, official documents, statements, and agreements) could identify the willingness of leaders to play an active role in promoting defense transformation.

\section{The Economic Issue of Defense Transformation}

To rethink the parameters of the debate on defense transformation, it is necessary to conduct an economic analysis to assess how affordable defense transformation is for small and medium-sized European members of NATO. The perspective of John M. (Jack) Treddenick, a professor of defense economics at the George C. Marshall Center in GarmischPartenkirchen, Germany, is the starting point for the analysis that follows. ${ }^{9}$ Because "the technologies define the opportunities and the economic tradeoffs define the possibilities," Treddenick considers that two important issues must be taken into account when conducting a budgetary analysis related to the affordability of transformation in terms of defense expenditure. The first issue is per capita defense expenditures (with per capita meaning per member of the armed forces, not the general population). The second issue, which is more difficult to calculate, is the balance among defense expenditures between costs for personnel, operation and maintenance, and capital (which is the sum of expenditures on equipment and infrastructure). Due to the lack of complete information about these types of expenditures, this analysis is only able to offer relevant and updated results through 2005 , and only for the NATO countries where these data are published.

Per capita defense expenditures are obtained by dividing total defense expenditures in U.S. dollars by a given country's armed forces strength (see Appendix 1). Being a crude measure of the degree to which a military force could afford to go through the defense transformation process, this number reflects more than pay and benefits, representing as well the average cost of equipping, training, maintaining, and deploying each member of the armed forces. At the same time, it gives the dimension of transformation that can be

9 Prof. John M. Treddenick, "Transformation: Who Can Afford It?" paper presented at the G.S. Rakovski Defense and Staff College, Sofia, Bulgaria, 4 July 2006. 
made in parallel with current operations, while maintaining readiness and modernizing existing capabilities.

Macroeconomic modes of measurement are frequently based on different assumptions, which create different models of analysis. In the case of defense expenditures, difficulties exist due to the variety of methods of calculating and reporting defense expenditures and defense budgets that are used in different countries. ${ }^{10}$ As a result, it is very difficult to make comparisons among states; a common standard is needed to accurately evaluate the public funds allocated to national defense and to international defense contributions.

Therefore, based on the model proposed by Professor Treddenick (and with his support), I will try in this essay to build a model for defense transformation that will work for small and medium-sized countries. For such countries, this could be achieved using the figures delivered to NATO. ${ }^{11}$ It is more difficult, however, if one attempts to compare the small and medium-sized NATO member states in Europe with the non-allied European countries (Austria, Cyprus, Ireland, Malta, Sweden, and Switzerland).

In the case of small and medium-sized European NATO members (these are listed in the Appendix 1 in a shadowed format), Norway is used as a benchmark. There are two reasons for this. First, this small country started its defense transformation process immediately after the 2002 NATO Summit in Prague, as indicated by the Norwegian leaders' statements at that time. ${ }^{12}$ Second, it is based on Norway's distribution of defense expenditures for personnel, operation and maintenance, and capital. According to Treddenick's approach, the ideal budgetary scenario for defense transformation is when the distribution of defense expenditures adheres to the following pattern: 40 percent for personnel, 30 percent for operation and maintenance, and 30 percent for capital (equipment and infrastructure). The closest countries to this ideal distribution are the United Kingdom and Norway. The U.K. is a large state, having a well-developed economy, and its results in defense transformation are very impressive. Norway is a small country, which has nevertheless made a commitment to implementing a defense transformation program. Its engagements in a variety of international missions, operating jointly with U.S. troops, have met expectations for the results of its defense transformation initiative.

There are some criticisms that can be made of using Norway as a benchmark. Perhaps the most salient is that Norway is too small to be a model. Given the small size of the country (and the fact that its economy is fueled by oil revenue), it had a much easier time successfully carrying out a defense transformation program. The figures do not show the

10 In this respect, see, Christopher Langton, ed., The Military Balance: 2006, International Institute for Strategic Studies (London: Routledge, Taylor and Francis Group, 2006), 11-12.

11 NATO, "Information for the Press" (8 December 2005), 5, 10; available at www.nato.int/docu/ pr/2005/p05-161.pdf.

12 Interview with Norway's Chief of Defense, General Sigurd Frisvold, by Joris Janssen Lok, “General Sigurd Frisvold - Norway's Chief of Defense," Jane's Defense Weekly (5 March 2003); see also another interview with Frisvold, in Joris Janssen Lok, "Norwegian Armed Forces Target Quality," Jane's International Defense Review (1 June 2003); "Norwegian Minister Calls for More SmallNation Partnerships," Jane's International Defense Review (1 April 2003); John Berg, "Country Briefing: Norway-High Priority," Jane's Defense (5-12 May 2004); Jane's Sentinel Security Assessment-Western Europe (13 January 2006). 
entire reality, however. The country cannot afford a full "tool box" of military capabilities; only selected expeditionary capabilities are affordable, according to de Wijk's approach as presented in Table 1. Thus, even though its size and situation render it unique (as, in fact, any chosen country would be), for methodological and scientific purposes Norway can be considered a benchmark for other small and medium-sized European countries.

Treddenick's assumption is that 80 percent of Norway's defense expenditures were for personnel and non-traded goods. Adjustments for defense purchasing power were estimated by multiplying 80 percent of U.S. dollar expenditures (the country in column 3 in Appendix 1), as reported by the ratio of Norway's domestic GDP (in dollars) at purchasing power parity per capita (Norway in column 12; in this case, Norway is the benchmark; in Treddenick's case, the U.S. is the benchmark) to U.S. GDP at purchasing power per capita (the country in column 12) and adding the remaining 20 percent of reported defense expenditures (the country in column 3 ). To go further, in case of each country, the resulting figure is divided by the current armed forces strength (column 7) and will result in adjusted per capita expenditure (column 13). The figures have the same meaning for all countries, and the expenditures could be ranked, showing a hierarchy among the countries.

The results in columns 8,11, and 14 of Appendix 1 are based on figures from another source in order to enable a comparison of all small European countries, both NATO members and non-members. ${ }^{13}$ Therefore, the results in column 14 are different from those in column 13, but the same principle is functioning in both cases.

All countries in Appendix 1 with a higher adjusted per capita defense expenditure than Norway's (i.e., those from rows 1 to 17 ) have the financial capacity for transformation, compared with the referent point of Norway's per capita defense expenditure. All those countries under the level of Norway's benchmark have (theoretically) two options in order to try to reach the same level of per capita defense expenditures: increasing their defense budget or reducing the number of personnel in their military. Until they accomplish either one of those two goals, defense transformation is not a financially viable proposition in these countries.

Changing the distribution among defense expenditures is a more modest alternative that could be suggested. It is related to the fact that a defense budget can be considered to be made up of three important categories of expenditures: personnel, operations and maintenance, and capital. Personnel expenditures include salaries and wages, as well as the costs of clothing and maintaining members of armed forces. For most countries, this type of expenditures represent the largest category in their defense budgets. Operations and maintenance includes the expenditures required to operate and maintain the country's inventory of military equipment and infrastructure. Capital investment expenditures are needed to replace old and expensive (in terms of operations and maintenance) equipment with new equipment and for modernizing and improving the current military infrastructure or building new facilities.

There is a strong possibility that a vicious circle could potentially arise between these categories - e.g., a large quantity of old equipment demands more money for operations and maintenance, which will result in less money being available for investment and per-

13 "Defense Budget for 2005," in The Military Balance: 2006, op. cit. 
sonnel, or labor-intensive investment expenditures will require more money for personnel, which will result in less money for operating and maintaining the present equipment. As mentioned above, the ideal ratio among the three categories is 40 percent for personnel, 30 percent for operations and maintenance, and 30 percent for investments. The NATO countries' current distributions are shown in Appendix 2. The tendency toward the ideal distribution of defense expenditures shows the potential for transformation possessed by a given country. This tendency can be achieved through continuous improvements in its stock of equipment and infrastructure, with the sufficient resources to both operate that equipment and maintain it in operational condition.

The existing differences among the countries shown in Appendix 2 related to the rates of defense expenditures in the three categories might be interpreted in a variety of ways. For example, in the case of Belgium, is the country simply more people-oriented than technology-oriented, or it is possible that the pensions that are included in the personnel expenditures have been added in order to increase spending in this category to an appropriate level in comparison to capital expenditures?

Subsequent to further analysis, according to Belgium's defense policy it is possible to interpret the high level of personnel expenditures as a preference for light units that are better suited for international peacekeeping missions than for classic war fighting or even RMA-based war. There are rich small countries (Luxembourg, Austria) that, due to the absence of any large-scale military threats, are able to place much more emphasis (and spend much more money) on other ways of ensuring their security than the classic military approach-including cooperative and regional security frameworks, and memberships in transcontinental and international organizations.

Another issue that arises from the figures in the Appendices is related to the category of capital expenditures, where the entire cycle of defense procurement must be considered. It is well known that the present procurement cycle is quite long - anywhere from five to fifteen years, depending on the system being acquired - and that the most expensive phase is research and development (R\&D). The R\&D phase itself can last well over a year, and the costs are very high. Certainly an appropriate analysis must take a historical perspective, considering the time evolution of defense expenditures (the Appendices are focused only on 2005 estimated defense spending; but, if it provides any consolation to the reader, from 2002-03, after the Prague Summit, the numbers are quite similar, reflecting the dominant trends in European defense spending).

Under these circumstances, the proposed modifications in defense expenditures must take into account the balance that all decision makers are forced to keep in their minds. ${ }^{14}$ On one hand, there are the security and defense risks and threats, and the appropriate ways to cope with them; on the other hand there are the budgetary constraints that apply to developing the appropriate capabilities to counter the identified threats. The proper solution could give rise to different political approaches.

Even though personnel reduction might be seen as the preferred method of bringing the distribution of defense expenditures into the appropriate alignment, other effects of such a decision should be taken into account. Because retired military personnel must be pre-

14 See Treddenick, "Transformation: Who Can Afford It?" 
pared to be incorporated into the civilian labor market without disturbing the overall economic balance, they need skills that are in demand in the private sector, which implies additional expenditures for their training. Concomitantly, the "ideal" allocation for investments in defense (new technologies for transformation) should increase the number of jobs in a nation through technological transfer, thus supporting the country's overall economic development.

Subsequent to the introduction of high technology — which represents the core of the Revolution in Military Affairs and is the single most influential factor in leading the military establishment to transformation - is the requirement for well trained and educated military personnel. This influences salaries in the military, and even in the private sector, as well as the ratio between military and civilian employees, the doctrine and training programs used in the military, and the organizational structures needed to best manage and deploy these revolutionary weapons (characterized by fewer people, smaller, flatter structures, and a higher degree of network orientation). All of these changes will require an entire new military culture, one that is nimbler and more entrepreneurial, rather than managerial and hierarchical.

Another political option for achieving the ideal distribution of defense expenditures is to increase the overall defense budget, in order to keep the same number of personnel. However, this is a very difficult issue to implement, due to a wide range of constraints. The general perception among the public is that the absence of a threat of large-scale military aggression means that any increase in defense spending is unjustified, as it would mean taking funds from other areas of spending, such as education, health care, or pensions. These assumptions are much closer to perceptions of a state's wealth than they are to any awareness of the costs of assuring national security abroad in a coalition of the willing, or of fighting against international terrorists with expensive network enabled capabilities.

\section{The Complete Picture}

All these assumptions are considered based on an analysis of the figures from the Appendixes. In addition to these numbers, the leaders and decision makers' statements must be taken into account in order to identify their political orientations, since we know that ultimately a nation's defense budget expresses the national leaders' commitment to a specific set of policies.

Putting all these facts and figures (quantitative and qualitative) into a single comprehensive picture, it is possible to arrange the countries in the chart below, although some explanations are necessary. This is only a "spot" assessment, trying to perceive the transformation process in a fixed position, if such a thing could exist; it is a snapshot of a constantly evolving set of factors. By contrast, a process could be assessed by comparing two similar frames of the process in distinct periods, such as years or months. The next path to follow might suggest the four quadrants on an economic and real facts analysis, although both of these categories have their limits in accuracy (figures), in the degree of correspondence between official statements and reality, and other areas. In the meantime, the countries could move from one quadrant to another, representing the dynamics of the defense transformation process seen in its three dimensions: social, political, and economic. 
The combination of these two types of analysis (quantitative and qualitative factors) are represented in a two dimensional graph which assigns the relative affordability of the transformation effort (in terms of resource allocations, or more simply put, the levels and distribution of defense expenditures among personnel, operation and maintenance, equipment and infrastructure) and the decision makers' level of willingness to commit to defense transformation.

At this point, the willingness of the leaders of the small countries could be identified, allowing them to be arranged on the diagram accordingly. For instance, Norwegian leaders can be considered to be oriented toward defense transformation; at the same time, others do not yet intend to implement any transformation in defense. Others, being more oriented toward continental Europe, might plan to promote Europe as a whole as an international power with an adequate military capability, more designed for crisis management, especially for reconstruction and stabilization operations and humanitarian aid. The diagram intentionally represents only the benchmark, Norway, because after this analysis anybody who is interested in the topic of defense transformation could position their own national military establishment accordingly.

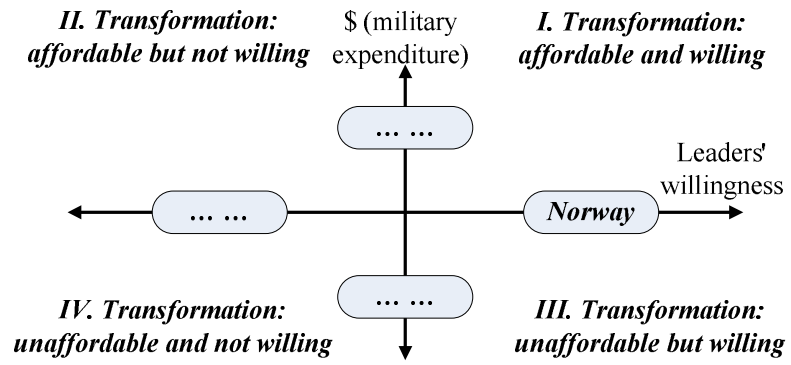

Figure 1: Locating a Country's Attitude Toward Defense Transformation

All the requirements call for appropriate people (especially their commitment to such a process, which could disturb the familiar relationship between military obedience and military competence), as well as a proper role, missions, and tasks for the new armed forces. Adequate resources and responsibilities could have higher costs than were budgeted for or estimated. Therefore, the opportunity cost is a very flexible concept, which shows what could be lost when something else is chosen. Even this is very difficult to accurately identify, due to a wide range of factors. The performance assessment represents the only method by which the needed corrections can be introduced in order to maintain progress toward the goals of the transformation process.

\section{The Results: Advantages and Disadvantages}

Now is the time to set out the advantages and disadvantages of defense transformation in small and medium-sized countries. The previous section offered the conditions that will allow one to assess the pros and cons. The two columns below will allow one to view them in parallel. 


\begin{tabular}{|c|c|}
\hline Advantages & Disadvantages \\
\hline \multicolumn{2}{|c|}{ EXTERNAL } \\
\hline \multicolumn{2}{|c|}{ Societal-Political-Economic-Technological and Military } \\
\hline $\begin{array}{l}\text { - The U.S. military's defense transforma- } \\
\text { tion model acts as a push factor, the ad- } \\
\text { vantages are perceived more than the } \\
\text { disadvantages } \\
\text { - The level of political support for trans- } \\
\text { formation (which represents the political } \\
\text { majority) could act as a push factor for } \\
\text { urging the necessary steps toward the } \\
\text { goal } \\
\text { - The commitment to defense transforma- } \\
\text { tion is perceived as expressing a willing- } \\
\text { ness to adopt hard-power approaches, } \\
\text { which could represent a commitment to } \\
\text { continue NATO's efforts toward trans- } \\
\text { formation } \\
\text { - At the same time, the current U.S. leader- } \\
\text { ship might perceive such commitment as } \\
\text { an expression of seriousness in the area } \\
\text { of bilateral cooperation; some gains } \\
\text { could come from this direction, consider- } \\
\text { ing that U.S. needs reliable and serious } \\
\text { partners } \\
\text { - For small countries, especially in stable } \\
\text { areas such as Europe, defense transfor- } \\
\text { mation offers possibilities for different } \\
\text { forms of cooperation in a variety of areas } \\
\text { related to military issues (see the coop- } \\
\text { erative arrangement among the Nordic } \\
\text { states: Norway, Denmark, and Sweden). } \\
\text { - Technology transfers must be considered } \\
\text { as developmental factors coming from } \\
\text { the will of political leaders to strengthen } \\
\text { their bilateral or multinational relations } \\
\text { forces to plug in to U.S., U.K., or Ger- } \\
\text { many-led coalitions in cases when they }\end{array}$ & $\begin{array}{l}\text { - The U.S. military's defense transforma- } \\
\text { tion model acts as a push factor, the dis- } \\
\text { advantages are perceived more than the } \\
\text { advantages } \\
\text { - The fact of defense transformation could } \\
\text { contribute to greater unease in unstable } \\
\text { regions, where a country's neighbors } \\
\text { might become suspicious of the power } \\
\text { increase in conventional capabilities } \\
\text { brought about by defense transformation } \\
\text { - In such areas, the countries that are un- } \\
\text { able to develop NCW capabilities might } \\
\text { choose alternatives, such as nuclear de- } \\
\text { terrence or nuclear capabilities, or other } \\
\text { WMD and unconventional war fighting } \\
\text { capabilities } \\
\text { - Defense transformation is an option only } \\
\text { for rich countries, which will enlarge the } \\
\text { gap between rich and poor countries due } \\
\text { to technological transfer and dual use of } \\
\text { technologies for both military and civil- } \\
\text { ians } \\
\text { - The critics of RMA consider that this is a } \\
\text { path that is only suitable in pursuit of the } \\
\text { ability to wage traditional warfare; in an } \\
\text { unconventional war, in stabilization and } \\
\text { reconstruction operations, and in humani- } \\
\text { tarian aid, the RMA is meaningless } \\
\text { - In any coalition there will always be a } \\
\text { leader who can impose his opinions, even } \\
\text { against his declared national objective } \\
\text { and interests; as a matter of fact, this } \\
\text { might limit the sovereignty of other na- } \\
\text { tions that have chosen to join the coali- } \\
\text { tion } \\
\text { - The dividends of a common action are }\end{array}$ \\
\hline
\end{tabular}

15 "The end of the Cold War has allowed the Nordic countries to engage in military cooperation within joint peacekeeping battalions and to consider joint procurement of hardware such as the joint program to purchase helicopters between Sweden, Denmark and Norway." Jane's Sentinel Security Assessment Western Europe (12 April 2007). 
use network-centric capabilities

- Because RMA as a backbone for defense transformation is going to be brought to bear in all three areas of modern military activity_classic war, stabilization and reconstruction efforts, and humanitarian aid - the ownership of these capabilities allows national military organizations to come in contact with the newest technologies, doctrines, logistics, and education and training

- Even though this transformation seems to be expensive, appropriate economic and budgetary approaches could help its implementation (offsets)

- RMA capabilities could be considered deterrence factors in the international arena not always shared equally or proportionally according to the efforts and resources expended

\section{INTERNAL}

\section{Political}

- Defense transformation represents a political construct introduced in the defense sector as a commitment by the political leadership to similar changes made in the U.S. military; in this case, political support is necessary for the success of this process

- The chosen defense transformation is based on public support for its elected political leaders, representing a matter of trust among politicians, civil society, and the military establishment; it is more likely to succeed in countries where the confidence in this national institution is high

- The political leaders could establish milestones for military leaders in order to measure their performance and to be in accordance with international commitments and agreements

- The commitment to defense transformation within the international framework obliges the national political leaders to respect their promises
- As a political construct it might exist only as long as the leaders that have introduced it are in power; a change in government could bring a new concept for military affairs, such as "metamorphosis," or "change management in defense," which could simply imply a continual adaptation of the military establishment

- Public support is needed in order to introduce such a process in the defense establishment, and in the countries reluctant to support their military, it is very difficult to gain this support

- There is a possibility to use this concept in an election in order to gain votes from the military and their advocates

- The process of defense transformation could be perceived as confirming a focus on hard power in the international arena

- Defense transformation is difficult to introduce in a country with a "peaceful" culture and a greater orientation toward soft-power approaches 


\section{Economic and Technological}

- The forms of cooperation among small countries in the area of network capabilities could bring new technological transfers, which would contribute to the countries' economic development

- Technology transfers could have an impact on the labor market, creating new jobs and contributing indirectly to economic growth

- The investment in RMA capabilities is a long-term cycle, and they could be used for both civilian and military purposes

- The spread of technology allows small countries to purchase high-tech equipment
- In terms of economic cooperation, it is possible that the dividends and the gains will not be shared equally or proportionally with the efforts and resources expended

- Technology transfers could take the form of older equipment, in line with countries' pursuit of affordable solutions

- The offsets between nations can be extremely complex, and might support only one part of a nation or its economy, instead of the whole

- RMA capabilities are expensive and require social sacrifices, considering the cost of investment and the effect on personnel reduction; these choices can have political and social implications

- The pace of technological upgrades and improvements is very rapid, which requires nations to make careful choices and explore alternatives

\section{Societal}

- Technology transfers could strengthen social solidarity among different professional groups

- RMA capabilities offer employment opportunities for people who are interested in high-tech fields but would not otherwise consider a professional military career
- RMA capabilities require specialists who must be hired away from civilian fields

- The entire human resources management cycle in the military - recruitment, retention (career development and motivational factors), and retirement - will face strong competition from the civilian labor market, since it is widely known that in developed countries, highly skilled people do not join the armed forces

- Making reductions in personnel in order to have money for capital expenditures could create more pressures on the labor market

\section{Military}

- Defense transformation could bring changes in the missions of the armed forces and in the functions of the services in order to increase their level of accept-
- Defense transformation affects the defense planning and procurement cycles, committing them to a state of permanent adaptation, because changing risks re- 
able performance as a result of efficiency and effectiveness measures

- Defense transformation creates smaller and leaner forces that are more rapid, flexible, agile, deployable, and precise in their strikes

- All military capabilities are integrated in a functional system of sensors, decision makers, and actors

- The entire picture of the battlefield is available for all, and front-line decisions could have strategic importance; data from the battlefield are processed instantaneously

- RMA capabilities reduce redundancy the war time, collateral damage, friendly fire, and allow more precise strikes

- Even though it has begun as a new way of waging war, defense transformation is going to be generalizable to all military operations: classic war, unconventional war, stabilization and reconstruction operations, and humanitarian aid

- Defense transformation is forcing the services to operate jointly

- Even through the new doctrines require new ways of training and education, with more expensive specialists, their influences and positive gains are synergistic, creating a new type of military elite

- The new force structures are flatter and create an entrepreneurial organizational culture

- Defense transformation contributes to defense planning efforts to offer better alternatives to present and future threats and risks

- Defense transformation with its RMA capabilities is easier to implement in small countries, since they have smaller bureaucratic structures than larger countries; at the same time, it could further reduce the size of the bureaucracy quire more concentrated efforts on designing and projecting military capabilities that are able to respond to a wide range of threats

- Defense transformation requires changes in doctrines and military training in order to create military personnel able to shift from the mode of warrior to the simultaneous modes of peacekeeper, negotiator, diplomat, and social worker

- A new form of training and education is needed involving highly specialized personnel, which is very expensive

- In terms of military operations, the required level of interoperability could demand uniformity in some fields; its lack might negatively affect the nation's logistics and command and communication systems

- The new professionals required for RMA capabilities are more expensive to retain, considering that they will have to be offered salaries that are competitive with offers from the private sector

- It is possible that senior military leaders will not accept these dramatic changes in military affairs, and might act as a factor working against defense transformation

- The autonomy in decision making at the lowest level could complicate the battlefield environment, and results might suffer in cases when soldiers are not well trained

- The training required for RMA capabilities takes much longer than traditional military training

- It is very difficult to measure and assess the achievements of defense transformation efforts

- The affordability of defense transformation is subject to budgetary constraints

- The opportunity costs for defense transformation are difficult to assess 
This kind of SWOT analysis can be used to show the advantages and disadvantages of implementing transformation in defense. As a change management process, defense transformation must include these widely accepted steps:

- Planning: defining goals for future organizational performance and deciding on the tasks and resources needed to attain them

- Organizing: assigning tasks, grouping tasks into departments, and allocating resources to departments

- Leading: using influence to motivate employees to achieve the organization's goals

- Controlling: monitoring employees' activities, keeping the organization on track toward its goals, and making corrections as needed.

At the same time, responsibilities for leaders must be established in order to assess whether outcomes are meeting agreed upon goals.

To be put into practice, from the very beginning the defense transformation concept must be thoroughly understood by both leaders and managers and subordinates, employees and followers, to avoid conceptual misunderstandings and mistakes. In context, defense transformation (according to the accepted definitions) is the process through which a nation's military forces will become more agile, flexible, and rapidly deployable; will be networked through C4ISR systems (including here the sensors, the decision makers, and the actors); will share situational awareness; will engage adversaries more precisely; and will act in a joint and interoperable manner.

A defense transformation document is needed as a part of defense planning, in order to demonstrate the leadership commitment to the effort. Consequently, this document must be in accord with the entire defense-planning framework, both on the national and international levels. Even though it is difficult to do accurately, conducting a performance assessment represents the only way through which the needed corrections can be made that will enable the transformation process to operate successfully.

\section{Conclusion}

The assessment of the advantages and disadvantages of defense transformation provided here will allow decision makers to chose the most appropriate defense policies in order to implement them in their national military establishments, according to their national interests and objectives. This will also enable leaders to use their own national military organizations as their nations' main security provider.

Defense transformation in small countries can be performed if the commitment exists among the top-level leaders; if the resources are found; and if the perceived gaps between military generations are taken into account, and efforts are made to solve them. Other forces working against transformation will come from different directions, both internal and external, and in many different dimensions: political, economic, social, technologic, and cultural. These factors must be acknowledged, and solutions to them must be found.

Defense transformation has a dialectical aspect. On one hand, it is a general process that has arisen as a result of the effect of the forces of globalization on domestic security and defense issues. As such, it is identical for all countries, having the same features. On 
the other hand, as a critical organizational process, defense transformation represents a unique response by each nation's defense institutions, a response that is crafted in order to cope with challenges coming from both internal and external sources. Therefore, seeing defense transformation from another perspective - that of the small and medium-sized countries' point of view-adds a much-needed dimension to the assumptions of the larger powers. 
THE QUARTERLY JOURNAL

Appendix 1: Armed Forces Per Capita Defense Expenditures 2005 (for NATO and EU Countries)

\begin{tabular}{|c|c|c|c|c|c|c|c|}
\hline \# & $\begin{array}{r}\text { E } \\
\text { Ac } \\
\text { Ex] }\end{array}$ & $\begin{array}{l}\text { Estimated } \\
\text { Actual Total } \\
\text { xpenditure* } \\
\text { (USDm) }\end{array}$ & $\begin{array}{c}\text { Defense } \\
\text { Budget*** } \\
\text { (USDm) } \\
\text { Military } \\
\text { Balance }\end{array}$ & $\begin{array}{c}\text { Defense } \\
\text { Expenditure } \\
\text { as percentage } \\
\text { of GDP* } \\
\text { (current prices) }\end{array}$ & $\begin{array}{l}\text { Population } \\
\text { (thousands) }\end{array}$ & $\begin{array}{c}\text { Current } \\
\text { Armed } \\
\text { Forces } \\
\text { Strength* } \\
\text { (thousands) }\end{array}$ & $\begin{array}{c}\text { Current } \\
\text { Armed } \\
\text { Forces } \\
\text { Strength } \\
\text { (thousands) }\end{array}$ \\
\hline & 2 & 3 & 4 & 5 & 6 & 7 & 8 \\
\hline 1 & Austria & & 2,290 & & 8,184 & & 39.9 \\
\hline 2 & Belgium & 4,769 & 3,350 & 1.3 & 10,364 & 38 & 36.9 \\
\hline 3 & Bulgaria & 640 & 631 & 2.5 & 7,450 & 42 & 51.0 \\
\hline 4 & Cyprus & & 280 & & 780 & & 10.0 \\
\hline 5 & Czech Republic & 2,31 & 2,190 & 1.8 & 10,241 & 26 & 22.2 \\
\hline 6 & Denmark & 3,694 & 3,200 & 1.4 & 5,432 & 20 & 21.1 \\
\hline 7 & Estonia & 210 & 205 & 1.7 & 1,332 & 3 & 4.9 \\
\hline 8 & Finland & & 2,700 & & 5,223 & & 28.3 \\
\hline 9 & Greece & 7,081 & 4,460 & 3.1 & 10,668 & 135 & 163.8 \\
\hline 10 & Hungary & 1,508 & 1,430 & 1.3 & 10,006 & 24 & 32.3 \\
\hline 11 & Iceland & & & & 296 & & 0.1 \\
\hline 12 & Ireland & & 959 & & 4,015 & & 10.4 \\
\hline 13 & Latvia & 199 & 279 & 1.4 & 2,290 & 6 & 5.2 \\
\hline 14 & Lithuania & 303 & 333 & 1.3 & 3,596 & 12 & 13.5 \\
\hline 15 & Luxembourg & 273 & 265 & 0.8 & 468 & 1.6 & 0.9 \\
\hline 16 & Malta & & 49 & & 399 & & 2.2 \\
\hline 17 & Netherlands & 10,268 & 9,700 & 1.7 & 16,407 & 50 & 53.1 \\
\hline 18 & Norway & 4,980 & 4,690 & 1.7 & 4,593 & 23 & 25.8 \\
\hline 19 & Portugal & 3,062 & 2,430 & 1.7 & 10,566 & 47 & 44.9 \\
\hline 20 & Romania & 1,957 & 1,960 & 2.0 & 22,329 & 79 & 97.2 \\
\hline 21 & Slovak Republic & lic & 828 & 1.8 & 5,431 & 19 & 20.2 \\
\hline 22 & Slovenia & 602 & 507 & 1.7 & 2,011 & 7 & 6.5 \\
\hline 23 & Sweden & & 5,600 & 1.2 & 9,001 & 124 & 27.6 \\
\hline 24 & Switzerland & & 3,820 & 3.2 & 7,489 & 499 & 4.3 \\
\hline
\end{tabular}

* Source: NATO, "Information for the Press" (8 December 2005), 5, 10.

** International Monetary Fund, World Economic Outlook Databases, April 2006 (data are for 2005); available at www.imf.org/external/pubs/ft/weo/2006/01/data/index.htm.

*** "Defense Budget for 2005," in The Military Balance: 2006, ed. Christopher Langton, The International Institute for Strategic Studies (London: Routledge Taylor and Francis Group, 2006). 


\section{Appendix 1}

\begin{tabular}{|c|c|c|c|c|c|c|}
\hline $\begin{array}{l}\text { Military and } \\
\text { civilian } \\
\text { personnel as } \\
\text { percentage of } \\
\text { labor force }\end{array}$ & $\begin{array}{l}\text { Per Capita } \\
\text { Defense } \\
\text { Expenditure } \\
\text { (USD) }\end{array}$ & $\begin{array}{c}\text { Per Capita } \\
\text { Defense } \\
\text { Expenditure } \\
\text { (USD) }\end{array}$ & $\begin{array}{l}\text { Per Capita } \\
\text { Income }^{* *}\end{array}$ & $\begin{array}{l}\text { Adjusted Per } \\
\text { Capita } \\
\text { Expenditure } \\
\text { (USD) }\end{array}$ & $\begin{array}{c}\text { Adjusted } \\
\text { Per Capita } \\
\text { Expenditure } \\
\text { (USD) }\end{array}$ & \# \\
\hline \multirow[t]{2}{*}{9} & 10 & 11 & 12 & 13 & 14 & \\
\hline & & 57.393 & 33615.161 & & 69.344 & 1 \\
\hline 0.9 & 125.500 & 90.786 & 31243.931 & 161.234 & 116.636 & 2 \\
\hline \multirow[t]{2}{*}{1.6} & 15.238 & 12.373 & 9223.262 & 59.041 & 47.938 & 3 \\
\hline & & 28.000 & 21232.209 & & 50.294 & 4 \\
\hline 0.8 & 89.000 & 98.649 & 18375.240 & 181.952 & 201.678 & 5 \\
\hline 1.0 & 184.700 & 151.659 & 34737.239 & 217.142 & 178.298 & 6 \\
\hline \multirow[t]{2}{*}{0.6} & 70.000 & 41.837 & 16414.034 & 158.535 & 94.751 & 7 \\
\hline & & 27.228 & 31207.669 & & 35.015 & 8 \\
\hline 3.3 & 52.452 & 27.228 & 22391.603 & 89.880 & 46.658 & 9 \\
\hline \multirow[t]{3}{*}{0.7} & 62.833 & 44.272 & 17404.673 & 134.919 & 95.064 & 10 \\
\hline & & 0.000 & 35586.320 & & 0.000 & 11 \\
\hline & & 92.212 & 40609.775 & & 95.399 & 12 \\
\hline 0.6 & 33.167 & 53.654 & 12621.599 & 95.692 & 154.801 & 13 \\
\hline 0.9 & 25.250 & 24.667 & 14158.421 & 65.492 & 63.979 & 14 \\
\hline \multirow[t]{2}{*}{0.9} & 170.625 & 294.444 & 69799.557 & 116.972 & 201.857 & 15 \\
\hline & & 22.273 & 19739.125 & & 42.696 & 16 \\
\hline 0.8 & 205.360 & 182.674 & 30861.515 & 266.593 & 237.143 & 17 \\
\hline 1.2 & 216.522 & 181.783 & 42364.220 & 216.522 & 181.783 & 18 \\
\hline 1.1 & 65.149 & 54.120 & 19334.599 & 127.229 & 105.691 & 19 \\
\hline 1.0 & 24.772 & 20.165 & 8784.991 & 100.522 & 81.825 & 20 \\
\hline 1.0 & 45.947 & 40.990 & 16040.740 & 106.269 & 94.803 & 21 \\
\hline \multirow[t]{3}{*}{0.9} & 86.000 & 78.000 & 21910.716 & 150.224 & 136.250 & 22 \\
\hline & 0.000 & 202.899 & 29898.076 & & 270.578 & 23 \\
\hline & 0.000 & 888.372 & 32570.872 & & 1102.06 & 24 \\
\hline
\end{tabular}

NATO countries 
THE QUARTERLY JOURNAL

Appendix 2: NATO Countries’ Armed Forces Per Capita Defense Expenditures 2005*

\begin{tabular}{|c|c|c|c|c|c|c|}
\hline$\#$ & Country & $\begin{array}{l}\% \text { devoted } \\
\text { to person- } \\
\text { nel expen- } \\
\text { ditures }\end{array}$ & $\begin{array}{c}\% \text { devoted } \\
\text { to operation } \\
\text { and mainte- } \\
\text { nance ex- } \\
\text { penditures } \\
\end{array}$ & $\begin{array}{c}\% \text { devoted to } \\
\text { capital } \\
\text { expenditures } \\
\text { (equipment }+ \\
\text { infrastructure) }\end{array}$ & $\begin{array}{l}\% \text { devoted to } \\
\text { equipment } \\
\text { expenditures }\end{array}$ & $\begin{array}{l}\% \text { devoted } \\
\text { to infra- } \\
\text { structure } \\
\text { expenditure }\end{array}$ \\
\hline & Ideal & 40.0 & 30.0 & 30.0 & & \\
\hline 1 & Belgium & 75.1 & 16.0 & 8.9 & 6.4 & 2.5 \\
\hline 2 & Bulgaria & 54.7 & 31.8 & 13.5 & 13.4 & 0.1 \\
\hline 3 & Canada & 45.8 & 36.3 & 17.9 & 14.2 & 3.7 \\
\hline 4 & Czech Republic & 49.7 & 28.9 & 21.4 & 11.6 & 9.8 \\
\hline 5 & Denmark & 52.2 & 27.4 & 20.4 & 18.0 & 2.4 \\
\hline 6 & Estonia & 31.0 & 40.4 & 28.6 & 13.3 & 15.3 \\
\hline 7 & France & 58.1 & 15.9 & 26.0 & 21.3 & 4.7 \\
\hline 8 & Germany & 59.3 & 21.6 & 19.1 & 15.1 & 4.0 \\
\hline 9 & Greece & 76.2 & 14.4 & 9.4 & 8.1 & 1.3 \\
\hline 10 & Hungary & 53.3 & 35.0 & 11.7 & 8.9 & 2.8 \\
\hline 11 & Iceland & & & & & \\
\hline 12 & Italy & 78.7 & 9.8 & 11.5 & 10.7 & 0.8 \\
\hline 13 & Latvia & 48,8 & 32.2 & 19.0 & 7.6 & 11.4 \\
\hline 14 & Lithuania & 57.4 & 24.0 & 18.6 & 14.9 & 3.7 \\
\hline 15 & Luxembourg & 72.2 & 11.7 & 16.1 & 14.6 & 1.5 \\
\hline 16 & Netherlands & 49.6 & 29.5 & 20.9 & 17.5 & 3.4 \\
\hline 17 & Norway & 41.7 & 30.5 & 27.8 & 22.5 & 5.3 \\
\hline 18 & Poland & 58.5 & 21.7 & 19.8 & 15.7 & 4.1 \\
\hline 19 & Portugal & 73.5 & 13.6 & 12.9 & 11.5 & 1.4 \\
\hline 20 & Romania & 54.6 & 22.2 & 23.2 & 21.3 & 1.9 \\
\hline 21 & Slovak Republic & 49.1 & 34.5 & 16.4 & 11.2 & 5.2 \\
\hline 22 & Slovenia & 57.8 & 22.6 & 19.6 & 17.1 & 2.5 \\
\hline 23 & Spain & 54.3 & 21.3 & 24.4 & 20.7 & 3.7 \\
\hline 24 & Turkey & 47.8 & 13.0 & 39.2 & 36.9 & 2.3 \\
\hline 25 & United Kingdom & 39.1 & 33.9 & 27.0 & 24.4 & 2.6 \\
\hline 26 & United States & 33.2 & 39.8 & 27.0 & 25.7 & 1.3 \\
\hline
\end{tabular}

* Source: NATO, "Information for the Press," (8 December 2005), 5, 10. 
SPRING 2008

\section{Bibliography}

Molis, Arunas. "The Role and Interests of Small States in Developing European Security and Defence Policy." Baltic Security \& Defence Review (2006). 